\title{
Downregulation of aquaporin 3 inhibits cellular proliferation, migration and invasion in the MDA-MB-231 breast cancer cell line
}

\author{
MUHAMMAD ARIF $^{1 *}$, PHILIP KITCHEN ${ }^{2}$, MATTHEW T. CONNER ${ }^{3}$, ERIC J. HILL ${ }^{3}$, \\ DAVID NAGEL ${ }^{1}$, ROSLYN M. BILL ${ }^{1}$, SIMON J. DUNMORE ${ }^{3}$, ANGEL L. ARMESILLA ${ }^{4}$, \\ STEPHANE GROSS ${ }^{1}$, AMTUL R. CARMICHAEL ${ }^{1}$, ALEX C. CONNER ${ }^{2 *}$ and JAMES E. BROWN ${ }^{5 *}$
}

\begin{abstract}
${ }^{1}$ School of Life and Health Science, Aston University, Birmingham B4 7ET; ${ }^{2}$ School of Clinical and Experimental Medicine, University of Birmingham, Birmingham B15 2TT; ${ }^{3}$ Research Institute for Healthcare Science, University of Wolverhampton; ${ }^{4}$ Cardiovascular Molecular Pharmacology Group, Research Institute in Healthcare Science, School of Pharmacy, Faculty of Science and Engineering, University of Wolverhampton, Wolverhampton WV1 1SB; ${ }^{5}$ Aston Research Centre for Healthy Ageing and Aston Medical Research Institute, School of Life and Health Sciences, Aston University, Birmingham B4 7ET, UK
\end{abstract}

Received June 16, 2017; Accepted December 11, 2017

DOI: $10.3892 / \mathrm{ol} .2018 .8759$

\begin{abstract}
Aquaporins are membrane proteins that regulate cellular water flow. Recently, aquaporins have been proposed as mediators of cancer cell biology. A subset of aquaporins, referred to as aquaglyceroporins are known to facilitate the transport of glycerol. The present study describes the effect of gene knockdown of the aquaglyceroporin AQP3 on MDA-MB-231 breast cancer cell proliferation, migration, invasion, adherence and response to the chemotherapeutic agent 5-fluorouracil. shRNA mediated AQP3 gene knockdown induced a $28 \%$ reduction in cellular proliferation $(\mathrm{P}<0.01)$, a $39 \%$ decrease in migration $(\mathrm{P}<0.0001)$, a $24 \%$ reduction in invasion $(\mathrm{P}<0.05)$ and a $25 \%$ increase in cell death at $100 \mu \mathrm{M} 5-\mathrm{FU}(\mathrm{P}<0.01)$. Analysis of cell permeability to water and glycerol revealed that MDA-MB-231 cells with knocked down AQP3 demonstrated a modest decrease in water permeability $(17 \%$; $\mathrm{P}<0.05)$ but a more marked decrease in glycerol permeability $(77 \%$; $\mathrm{P}<0.001)$. These results suggest that $\mathrm{AQP} 3$ has a role in multiple aspects of breast cancer cell pathophysiology and therefore represents a novel target for therapeutic intervention.
\end{abstract}

Correspondence to: Dr James E. Brown, Aston Research Centre for Healthy Ageing and Aston Medical Research Institute, School of Life and Health Sciences, Aston University, Aston Street, Birmingham B4 7ET, UK

E-mail: j.e.p.brown@aston.ac.uk

Dr Alex C. Conner, School of Clinical and Experimental Medicine, University of Birmingham, Birmingham B15 2TT, UK

E-mail: a.c.conner@bham.ac.uk

${ }^{*}$ Contributed equally

Key words: aquaporin, AQP3, breast cancer, proliferation, migration, invasion, glycerol

\section{Introduction}

Breast cancer is the leading cause of female mortality in the Western world (1) and is the most common form of cancer in the UK. One million diagnoses were made worldwide in 2011 (2), of which over 40,000 new cases were diagnosed in the UK (3). Importantly, metastatic relapse is a key predictor of survival with fewer than $5 \%$ of women with metastatic breast cancer being disease free at five years (4). Although significant improvements in the management of primary and metastatic breast cancers have been made, the search for a successful and less toxic treatment of the metastatic breast cancer is on-going.

The aquaporin (AQP) family of membrane protein channels facilitates rapid water transport across all cell membranes, thereby maintaining body water homeostasis (5). Thirteen human AQPs have been identified to date (6), which form two distinct sub-groups: Classical AQPs (AQP0, 1, 2, 4, 5, 6 and 8) that solely transport water, and aquaglyceroporins (AQP3, 7, 9 and 10) that additionally transport small, uncharged molecules such as glycerol and urea (6).

The aquaglyceroporin AQP3 is expressed widely in the body and has been implicated in an increasing number of physiological and pathophysiological processes. These include metabolism, type 2 diabetes and skin elasticity (7). AQP3-null mice have also been demonstrated to have a reduced capacity for wound healing (8).

Recent evidence has suggested that several AQP family members are involved in carcinogenesis, with altered expression of AQPs being detected in several types of cancer (9). AQPs are now known to regulate cancer cell proliferation, migration, angiogenesis and metastasis (10-12). AQP3 has further been suggested to have a role in bladder (13), colorectal (14), gastric $(15,16)$, lung $(17,18)$ and skin $(19)$ cancers. In breast cancer, an increased expression of AQP3 was reported compared to healthy border tissue, although the reasons for this observation are unclear $(20,21)$. The role of AQP3 in breast cancer is however controversial, as recent evidence has suggested that AQP3 expression may be linked 
to disease survival in HER2 positive breast cancer (22) and a study recently reported that AQP3 gene silencing significantly reduced oestradiol-induced profilferation, invasion and migration in a cell model of breast cancer (23). It is possible that increased AQP3 expression in breast cancer cells may facilitate glycerol transport into the cell. This may then contribute to the generation of ATP (19), providing cancer cells with increased energy required for proliferation and tumourigenesis. Alternatively, these observations may be explained by as yet unassigned effects of water transport through the cell. Triple-negative breast cancers are associated with poor survival outcomes, and have been linked to a lower 5-year survival rate (24). This is due to lack of response to therapies such as tamoxifen and Herceptin as well as rapid tumour development and metastasis (25) and as such makes studying triple negative breast cancer a priority.

These findings suggest that AQP3 may be involved in several key processes that are important in breast cancer cell biology. In the present study AQP3 gene silencing was used to establish a role for this aquaglyceroporin in breast cancer cell pathophysiology. The effects on cellular proliferation, migration, invasion and response to a chemotherapeutic agent in the invasive human breast cancer cell model MDA-MB-231 were compared.

\section{Materials and methods}

Cell culture and reagents. Reagents were purchased from Sigma-Aldrich (Dorset, UK) unless stated otherwise. MDA-MB-231 human breast cancer cells were purchased from ATCC. Cells were routinely cultured in RPMI-1640 (PAA Laboratories Ltd., Somerset, UK) supplemented with $10 \%$ foetal bovine serum (FBS; PAA Laboratories Ltd., Somerset, $\mathrm{UK}), 50 \mathrm{IU} / \mathrm{ml}$ penicillin, $50 \mu \mathrm{g} / \mathrm{ml}$ streptomycin and $2 \mathrm{mM}$ glutamine at $37^{\circ} \mathrm{C}$ in a $5 \% \mathrm{CO}_{2}$ incubator. 5 -FU was purchased from Tocris Bioscience (Bristol, UK).

Transfection and selection of stably expressing AQP3 shRNA clones. shRNA plasmids for AQP3 were purchased from Origene, USA. Of the four plasmid sequences, the plasmid that caused the most significant downregulation was chosen for production of stably expressing cells (termed shAQP3 cells). Transfection of AQP3 and control shRNA plasmids [including a red fluorescent protein (RFP) sequence and a puromycin-N-acetyl transferase gene located downstream of the SV40 promoter] into MDA-MB 231 cells was performed with Genjet transfection reagent $\left(\right.$ GenJet $^{\mathrm{TM}}$ DNA in vitro Transfection Reagent; SignaGen Laboratories, Rockville, MD, USA). Cells were subsequently treated with $2 \mu \mathrm{g} / \mathrm{ml}$ puromycin for 2 weeks before colonies of puromycin resistant cells were picked using glass colony selection cylinders. Cells then underwent a 5-fold serial dilution with the last dilution being assessed for RFP expression and sub-culturing.

Reverse transcription-quantitative polymerase chain reaction $(R T-q P C R)$ and western blot analysis of AQP expression. RNA was isolated from all samples using a proprietary RNA isolation kit (E.Z.N.A. ${ }^{\circledR}$ Total RNA kit I; Omega Bio-Tek, Inc., Norcross, GA, USA). Quantification of total RNA was performed using a Nanodrop spectrophotometer (Thermo
Fisher Scientific, Inc., Leicester, UK). $1 \mu \mathrm{g}$ total RNA from each sample was reverse transcribed using a proprietary cDNA synthesis kit (Primerdesign Ltd., Cambridge, UK) for $20 \mathrm{~min}$ at $55^{\circ} \mathrm{C}$. Resulting cDNA was diluted 1 in 10 and subjected to SYBR $^{\circledR}$-Green Real-Time PCR using pre-validated sequence specific primers for AQPs purchased from Primerdesign Ltd. Housekeeping genes that were used to normalise data were chosen from a pool of candidate normalising genes with the two most stably expressed genes being employed ( $\beta$-actin and YWHAZ). Samples were analysed using Precision SYBR-Green PCR Mastermix (Primerdesign Ltd.) and a Stratagene MX3000P thermal cycler (Stratagene, Stockport, UK). Comparisons were made for each sample between the average crossing point $(\mathrm{Cq})$ obtained from the genes of interest and the geometric mean of the $\mathrm{Cq}$ obtained from the housekeeping genes, $\beta$-actin and YWHAZ (giving $\Delta \mathrm{Cq}$ ).

For protein analysis, cells were lysed using RIPA buffer (Merck Millipore, Watford, UK) and insoluble material removed by centrifugation at 13,000 RCF, with the insoluble pellet being discarded. The protein content of the lysate was quantified using a modified Lowry method (DC Protein Assay; Bio-Rad Laboratories Ltd., Watford, UK) and photometrically measured at $690 \mathrm{~nm}$. All samples were compared to a standard curve using BSA of a known concentration. Briefly, for analysis of AQP3 protein expression, $60 \mu \mathrm{g}$ protein per sample was denatured and separated using $12 \%$ SDS-PAGE. Following SDS-PAGE, protein was transferred to a pure nitrocellulose blotting membrane (VWR International Ltd., Leicestershire, UK) at $100 \mathrm{~V}$ for $1 \mathrm{~h}$ and subsequently blocked using 5\% non-fat milk (Marvel) in $1 \mathrm{X}$ TBS buffer (Sigma-Aldrich) containing 0.1\% Tween-20 (TBS-T). After blocking, the membrane was washed three times in TBS-T and once in TBS buffer and then incubated overnight at $4^{\circ} \mathrm{C}$ with rabbit anti-human AQP3 antibody (cat. no. sc-20811; Santa Cruz Biotechnology, Inc., Dallas, TX, USA). The membrane was again washed before incubation at room temperature for $1 \mathrm{~h}$ with a goat anti-mouse IgG-HRP conjugated secondary antibody (Abcam, Cambridge, UK). Following secondary antibody incubation, the membrane was washed and subsequently exposed to the EZ-ECL chemiluminescence western blotting detection system (Geneflow, Lichfield, UK) for $5 \mathrm{~min}$. Bands were then visualised using the GBOX HR 16 imaging system and GeneSys software (Geneflow). Blots were then stripped and probed for tubulin (using an anti-tubulin antibody from Abcam; cat. no. ab6046) as a loading control. Band density was measured using Image J and AQP3 band density was calculated as a ratio of AQP3: Tubulin.

Cellular proliferation assay. All cell counts were performed using a Countess ${ }^{\circledR}$ Automated Cell Counter (Thermo Fisher Scientific, Inc.). To measure cellular proliferation, wild type MDA-MB-231 and shAQP3 cells were grown to confluence and serum-starved overnight to synchronise the cell cycle. $2 \times 10^{5}$ cells were seeded into $75 \mathrm{~cm}^{2}$ cell culture vessels and allowed to grow for $72 \mathrm{~h}$ under standard conditions. Cells were subsequently detached using Accutase (PAA Laboratories Ltd.) before being re-counted. For each count, both chambers of a Countess slide were used and an average figure recorded. 
Cellular migration assays. Two separate methodologies were employed to assess cell migration. For the wound scratch assay (26) WT and shAQP3 cells were seeded into 6-well plates, grown to confluence then serum-starved overnight. A sterile $20 \mu$ l pipette tip was used to produce a cross shaped scratch in the middle of each well. Images were taken using a Leica DMI4000 B inverted microscope at time points 0, 24, 48 and $72 \mathrm{~h}$. Wound scratch analysis software TScratch was used to calculate the percentage wound closure for the different cell types at all time points (27).

Cellular migration was also assessed using a Cell-IQ ${ }^{\circledR}$ automated image capture system (CM Technologies, Tampere, Finland). WT and shAQP3 cells were seeded into 6-well plates and allowed to become confluent prior to overnight serum starvation. Cells were then scratched with a $20 \mu \mathrm{l}$ pipette tip, and washed twice with HBBS to remove floating cells. Cells were treated with $5 \mu \mathrm{g} / \mathrm{ml}$ mitomycin $\mathrm{C}$ to inhibit cellular proliferation. The plates were placed on the Cell-IQ ${ }^{\circledR}$ system and two regions of interest (ROI) were selected for each cell type. The images were obtained every $15 \mathrm{~min}$ continuously over a $24 \mathrm{~h}$ period. Cell migration was expressed as the percentage of the wound closure relative to the initial wound scratched area. Digitised images were then analysed by Cell-IQ Analyser ${ }^{\mathrm{TM}}$ software to calculate the percentage of wound closure. Fig. 3C represents the mean of three separate experiments.

Cellular invasion assay. Cell invasion assays were carried out with WT and shAQP3 cells in 96-well transwell plates with $8 \mu \mathrm{m}$ pores using the Cultrex ${ }^{\circledR}$ BME Cell Invasion Assay system (R\&D Systems Abington, UK). Cells were starved in serum-free medium for $18 \mathrm{~h}$ before analysis. Basement membrane extract (BME) was used to coat transwell plates for $4 \mathrm{~h}$ at $37^{\circ} \mathrm{C}$ in a $\mathrm{CO}_{2}$ incubator before being aspirated and 50,000 cells were subsequently seeded per transwell. 10\% FBS medium was added to the bottom chambers. Cells were incubated at $37^{\circ} \mathrm{C}$ in $\mathrm{CO}_{2}$ incubator for $48 \mathrm{~h}$. After $24 \mathrm{~h}$ the top and bottom chambers of the invasion devices were carefully aspirated, washed and Calcein-AM (in a cell lysis buffer) was added to the bottom chambers and incubated at $37^{\circ} \mathrm{C}$ in $\mathrm{CO}_{2}$ incubator for $1 \mathrm{~h}$. The top chambers were removed and plates were read on a SPECTRAmax ${ }^{\circledR}$ GEMINI-XS Spectrofluorometer (Molecular Devices Corporation, Sunnyvale, CA, USA) at $485 \mathrm{~nm}$ excitation, $520 \mathrm{~nm}$ emission.

Cellular adhesion assay. Wild type and shAQP3 cells were seeded into 96-well plates coated with fibronectin (R\&D Systems), where adherent cells were captured. After $4 \mathrm{~h}$ unbound cells were washed away, and the adherent cells are were exposed to Calcein-AM solution before fluorescence was read at on a SPECTRAmax ${ }^{\circledR}$ GEMINI-XS Spectrofluorometer (Molecular Devices Corporation) at $485 \mathrm{~nm}$ excitation, $520 \mathrm{~nm}$ emission.

Cell viability assay. For analysis of 5-FU induced cell death, WT and shAQP3 cells were seeded into 96-well plates at a density of 10,000 cells per well. After $48 \mathrm{~h}$ cells were treated with 5-FU at a concentration of $100 \mu \mathrm{mol} / 1$ for $48 \mathrm{~h}$. A proprietary resazurin-based cell viability assay was used to measure induced cell death following the manufacturer's protocol (PrestoBlue ${ }^{\mathrm{TM}}$; Thermo Fisher Scientific, Inc.) using a SPECTRAmax ${ }^{\circledR}$ GEMINI-XS Spectrofluorometer.

Fluorescent cell swelling assay. In order to assess transport of water and glycerol into AQP3 silenced cells, a Calcein AM-based cell swelling assay was employed. Briefly, $2.5 \times 10^{4}$ cells were seeded in triplicate in 96-well tissue culture treated plates (Falcon) $24 \mathrm{~h}$ before the experiment. Cells were subsequently incubated with $5 \mu \mathrm{M}$ calcein-AM (Molecular Probes; Invitrogen Life Technologies) in complete cell culture media for $90 \mathrm{~min}$. Excess calcein-AM was removed by washing. Calcein AM fluorescence time-series were measured in a BioTek Synergy HT plate reader using the $495 \mathrm{~nm}$ excitation and $515 \mathrm{~nm}$ emission filters, with the internal temperature held at $37^{\circ} \mathrm{C}$.

For water permeability analysis fluorescence readings were taken every $50 \mathrm{~ms}$. After $5 \mathrm{sec}, 75 \mu \mathrm{l}$ of hypotonic culture media $\left(170 \mathrm{mOsm} / \mathrm{kg} \mathrm{H}_{2} \mathrm{O}\right)$ was added to the $75 \mu \mathrm{l}$ media $\left(340 \mathrm{mOsm} / \mathrm{kg} \mathrm{H}_{2} \mathrm{O}\right)$ already on the cells (to give a final extracellular osmolality of $255 \mathrm{mOsm} / \mathrm{kg} \mathrm{H}_{2} \mathrm{O} ; \Delta \mathrm{Osm}=85$ $\mathrm{mOsm} / \mathrm{kg} \mathrm{H}_{2} \mathrm{O}$ ) using the plate reader injector system, at a rate of $350 \mu \mathrm{l} / \mathrm{sec}$. Fluorescence was then measured for $49.8 \mathrm{sec}$. For glycerol permeability analysis, fluorescence readings were taken every $100 \mathrm{~ms}$ due to the slower rate of swelling associated with glycerol transport. After $10 \mathrm{sec}, 75 \mu \mathrm{l}$ of an isoosmotic ( $340 \mathrm{mM}$ in $\mathrm{ddH}_{2} \mathrm{O}$ ) glycerol solution was added to the $75 \mu 1$ media already on the cells using the plate reader injector system, at a rate of $350 \mu \mathrm{l} / \mathrm{sec}$. Fluorescence was then measured for $99.9 \mathrm{sec}$. As the glycerol solution was isoosmotic, any changes in cell volume could be attributed to changes in intracellular osmolality and subsequent osmosis due to glycerol uptake. As a negative control, an isoosmotic mannitol solution $\left(340 \mathrm{mM}\right.$ in $\left.\mathrm{ddH}_{2} \mathrm{O}\right)$ was injected, and no change in fluorescence intensity was observed (data not shown). All solution osmolalities were measured with an Osmomat 3000 freezing point depression osmometer (Gonotec, Berlin, Germany). Fluorescence readings from cells not loaded with calcein AM were taken as background and subtracted from the raw data. Data were normalised to the average of the first five readings after injection. Exponentially decaying growth curves of the form $\mathrm{C}$-Ae-kt were fitted subject to the constraint $\mathrm{C}-\mathrm{A}=1$, using the Solver tool in Microsoft Excel. Curves were fitted to 3 fluorescence traces per experimental repeat.

Statistical analysis. Statistical analysis of data was performed using GraphPad Prism 6 software (GraphPad Software, Inc., La Jolla,. CA, USA). One-way analysis of variance (ANOVA) with Tukey's post hoc test for comparisons of $\geq 3$ groups or Student's t-test for comparisons of $<3$ groups were performed for the statistical analysis between experimental conditions. $\mathrm{P}<0.05$ were considered significant as indicated by *; $\mathrm{P}<0.01$ are indicated by ${ }^{* *}$; and $\mathrm{P}<0.001$ are indicated by ${ }^{* * *}$. Where $\mathrm{n}$ is stated, $\mathrm{n}$ refers to the number of separate biological replicates assessed.

\section{Results}

$A Q P$ expression in primary human breast tissue and $M D A-M B-231$ cells. Expression of all 13 human AQP family members was investigated in the invasive breast cancer cell 
A

\begin{tabular}{|c|c|}
\hline AQP & $\begin{array}{c}\text { Mean } \mathbf{C}_{\mathbf{t}} \\
\text { value }\end{array}$ \\
\hline $\mathbf{0}$ & $30.02 \pm 0.72$ \\
\hline $\mathbf{1}$ & $32.82 \pm 1.07$ \\
\hline $\mathbf{2}$ & nil \\
\hline $\mathbf{3}$ & $24.001 \pm 1.89$ \\
\hline $\mathbf{4}$ & $31.43 \pm 0.40$ \\
\hline $\mathbf{5}$ & $31.34 \pm 0.81$ \\
\hline $\mathbf{6}$ & $30.58 \pm 0.82$ \\
\hline $\mathbf{7}$ & $30.30 \pm 0.38$ \\
\hline $\mathbf{8}$ & $31.32 \pm 0.92$ \\
\hline $\mathbf{9}$ & $32.92 \pm 1.34$ \\
\hline $\mathbf{1 0}$ & nil \\
\hline $\mathbf{1 1}$ & $27.52 \pm 0.49$ \\
\hline $\mathbf{1 2}$ & $28.89 \pm 0.19$ \\
\hline
\end{tabular}

B
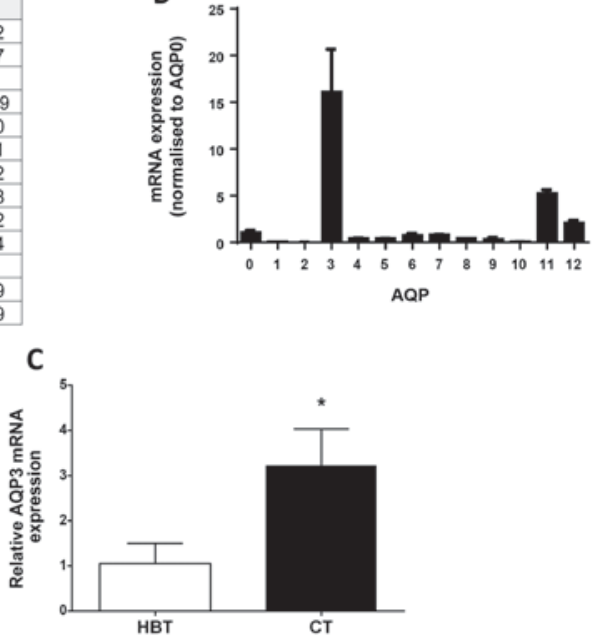

Figure 1. AQP gene expression in breast cancer biopsies and MDA-MB-231 cells. (A) qPCR analysis of AQP family mRNA expression in breast cancer biopsy samples. Data expressed as mean Cq value \pm SEM (n=8). (B) Graphical representation of qPCR expression in MDA-MB-231 cells with all AQPs normalised to the expression level of AQP0. Bars represent mean \pm SEM (C) qPCR analysis of AQP3 mRNA expression in primary healthy breast tissue (HBT) and matched cancerous tissue (CT). Bars represent mean expression levels normalised to HBT $(n=6) .{ }^{*} \mathrm{P}<0.05$ vs. HBT.

line MDA-MB-231 using SYBR ${ }^{\circledR}$-Green Real-Time PCR analysis. AQP3 was the most abundant transcript of all AQP family members, with an average $C_{t}$ value of $24( \pm 0.89$, Fig. 1A and B). Analysis of AQP3 gene expression in primary human breast tissue showed a threefold higher level of AQP3 expression (Fig. 1C; $\mathrm{P}=0.018, \mathrm{n}=6$ ) in cancerous breast tissue compared to healthy border tissue. After shRNA-mediated AQP3 gene silencing, both qPCR and western blotting (Fig. 2) were used to assess gene knock-down.

Semi-quantitative western blotting band density analysis demonstrated that protein expression was reduced by $60 \%$ $( \pm 12 \%)$ in the AQP3 shRNA stable clone (shAQP3) compared to WT cells $(\mathrm{P}=0.012)$.

shRNA-mediated AQP3 gene silencing significantly reduces $M D A-M B-231$ cellular proliferation. AQP3 has been identified as a regulator of cellular proliferation in several cell types (8,28-30). The effect of silencing AQP3 in MDA-MB-231 cells on cellular proliferation rate was measured. Analysis of total cell count $72 \mathrm{~h}$ post-seeding showed that AQP3-silenced cells (shAQP3) had a $28 \%$ reduction $( \pm 9 \%)$ in cell numbers compared to WT cells ( $\mathrm{P}=0.01$, Fig. 3 ). From repeated counting at 24, 48 and $72 \mathrm{~h}$, the doubling time of cells was calculated as follows: $\mathrm{WT}=30.98 \mathrm{~h}$, shAQP3=39.27 h $(\mathrm{P}<0.05$ for shAQP3 vs . $\mathrm{WT} ; \mathrm{n}=8)$. AQP3 silencing therefore significantly decreased the rate of cellular proliferation in MDA-MB231 cells resulting in an increased doubling time. This suggests that AQP3 is involved in MDA-MB-231 cell proliferation, and may therefore represent a novel target for reducing levels of breast cancer cell growth.

Silencing AQP3 mRNA causes a significant reduction in cellular migration. The role of AQP3 in cell migration and wound healing is well established $(8,14,28)$. The present study therefore assessed the impact of AQP3 gene silencing of
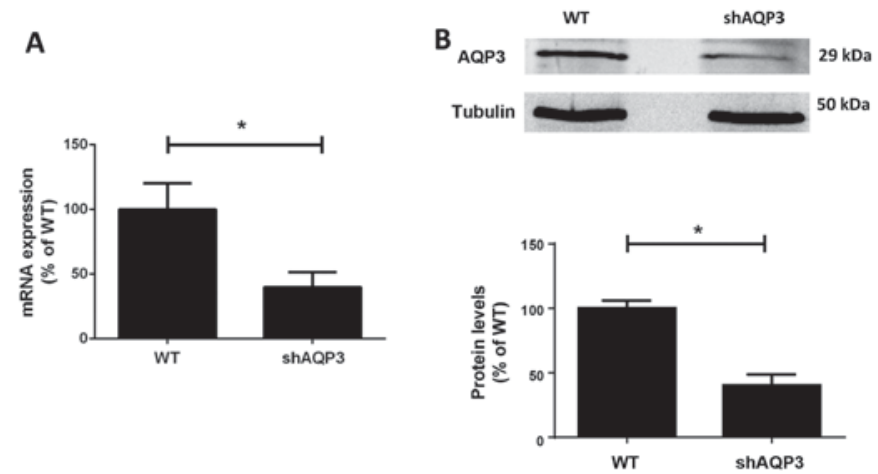

Figure 2. AQP expression after shRNA-mediated gene-silencing in MDA-MB-231 cells. (A) qPCR analysis of AQP3 mRNA expression levels in stably shRNA transfected MDA-MB-231 cells (shAQP3) compared to wild type (WT) cells $(n=8)$. (B) AQP3 protein expression in shAQP3 cells measured by semi-quantitative western blotting, $(n=6)$. $P<0.05$. Bars represent mean \pm SEM.

MDA-MB-231 cells, a cell line known to have migratory potential (31). In order to assess cell migration, WT and shAQP3 cells were subjected to two assays; a wound scratch assay, an established measure of MDA-MB-231 cell migration $(31,32)$ and analysis using the Cell IQ system. For the wound scratch assay, after $72 \mathrm{~h}$, WT cells showed a wound closure of $58 \%$ ( $\pm 6 \%$ ), $n=5$ (Fig. 4). Wound closure was significantly reduced in the shAQP3 cells to just $25 \%( \pm 6 \%$; $\mathrm{P}=0.001)$. Using the Cell IQ system, in conjunction with mytomycin $\mathrm{C}$ treatment to inhibit cellular proliferation, shAQP3 cells showed a $39 \%$ reduction in cellular migration after $24 \mathrm{~h}$ compared to WT cells. These data demonstrate that AQP3 is an important regulator of MDA-MB-231 cell migration, and that cell migration can be potently inhibited in vitro by targeting AQP3 expression. As mytomycin $\mathrm{C}$, a mitotic inhibitor, was used for the CellIQ assay these results suggest that the difference in wound closure observed was not due to the effects of AQP3 silencing on proliferation.

Stable AQP3-silenced cells show decreased levels of cellular invasion but unchanged cellular adhesion. The process of metastasis, the spread of cancer cells from a primary site to distant parts of the body, is initiated by cellular invasion and is considered a pivotal aspect of cancer mortality (33). In order to assess the levels of invasiveness of cells in which AQP3 had been silenced, proprietary BME- and collagen-based cellular invasion assays was used, whereby cells were challenged using $\mathrm{BME}$ or collagen coated transwell dishes through which they were required to invade in order to reach a bottom chamber. After a $72 \mathrm{~h}$ incubation period, shAQP3 cells showed a significantly reduced level of invasion through BME- and collagen coated plates of $76 \%( \pm 3 \%)$ and $77 \%( \pm 4 \%)$ respectively compared to WT cells (Fig. 5A and B, $\mathrm{n}=6$ ).

Cellular adhesion plays an important part in cancer progression and metastasis (34) with circulating cancer cells ultimately interacting with endothelial cells, leading to extravasation (35). WT and shAQP3 cells were seeded into fibronectin coated plates for $4 \mathrm{~h}$ to assess levels of cellular adhesiveness. Analysis of Calcein-AM staining in each well after this period showed that there was no significant difference in the levels of cellular adhesion between the two cell types 


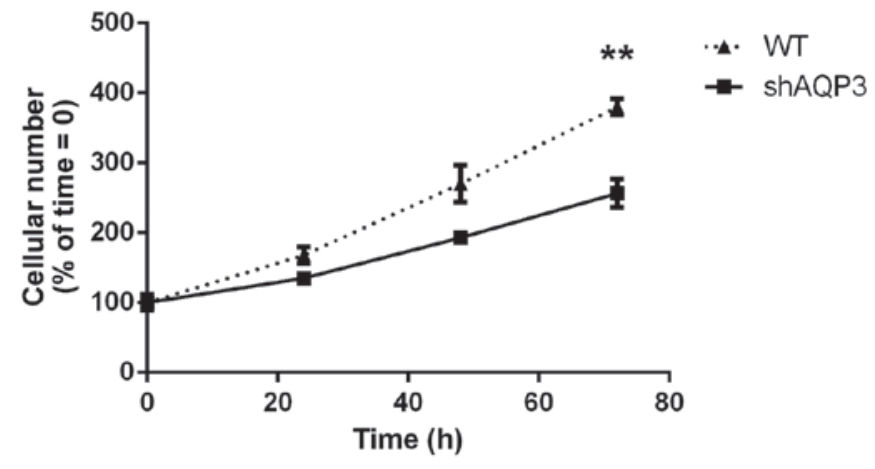

Figure 3. Reducing AQP3 expression inhibits cellular proliferation rate. Cell viability assay comparing stable AQP3 knock-down MDA-MB-231 cells (shAQP3) with WT at 24,48 and $72 \mathrm{~h}(\mathrm{n}=8) .{ }^{* *} \mathrm{P}<0.01$ vs. shAQP3. Data points represent mean \pm SEM.

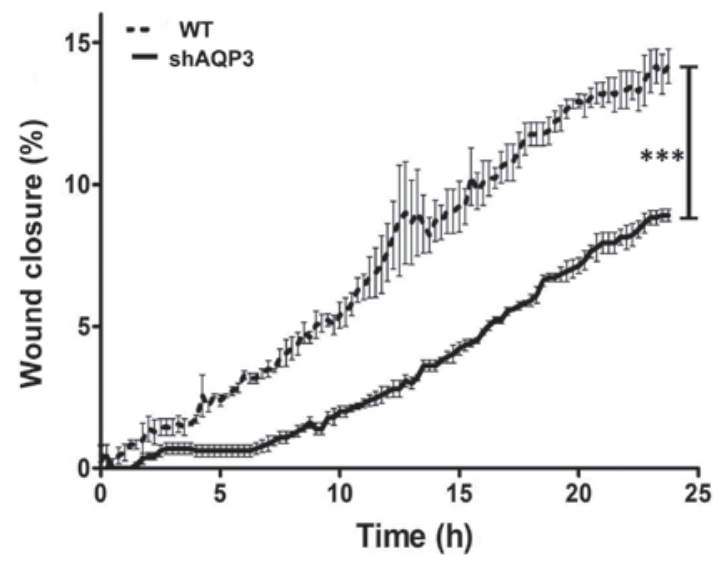

Figure 4. AQP3 silenced cells exhibit reduced migration rate. Analysis of cellular migration using the CellIQ imaging and automated analysis system after $24 \mathrm{~h}(\mathrm{n}=3)$. Data represents mean $\pm \mathrm{SD}$. ${ }^{* * *} \mathrm{P}<0.0001$.

( $\mathrm{P}=0.56$, Fig. $5 \mathrm{C} ; \mathrm{n}=8$ ) suggesting that $\mathrm{AQP} 3$ does not have a role in MDA-MB-231 cell adhesion.

AQP3 silencing increases 5-FU induced cell death. 5-FU is a fluoropyrimidine pro-drug commonly given to treat bowel, breast or stomach cancer (36). A regulatory role for AQP3 in chemotherapy-induced breast cancer cell death has previously been suggested (20). We therefore investigated the role of AQP3 in cell death by exposing WT and shAQP3 cells to a range of 5-FU concentrations for $48 \mathrm{~h}$ and subsequently measuring cell viability. shAQP3 cells showed significantly lower (maximal 25\% reduction, $\mathrm{P}<0.05 ; \mathrm{n}=5$ ) levels of cell viability at all 5 -FU concentrations tested when compared to WT cells (Fig. 6), suggesting that AQP3 has a cytoprotective effect in breast cancer cells.

AQP3 silencing markedly decreases glycerol permeability in MDA-MB-231 cells. As AQP3 is known to be permeable to both water and glycerol, analysis of the transport of both of these molecules was performed in WT and shAQP3 cells to provide information regarding the likely role of AQP3 in these cells. Analysis of cellular fluorescence using cells pre-exposed to calcein AM (adapted from (37)) showed that shAQP3 cells displayed a significant decrease of $17 \%$ in cellular permeability
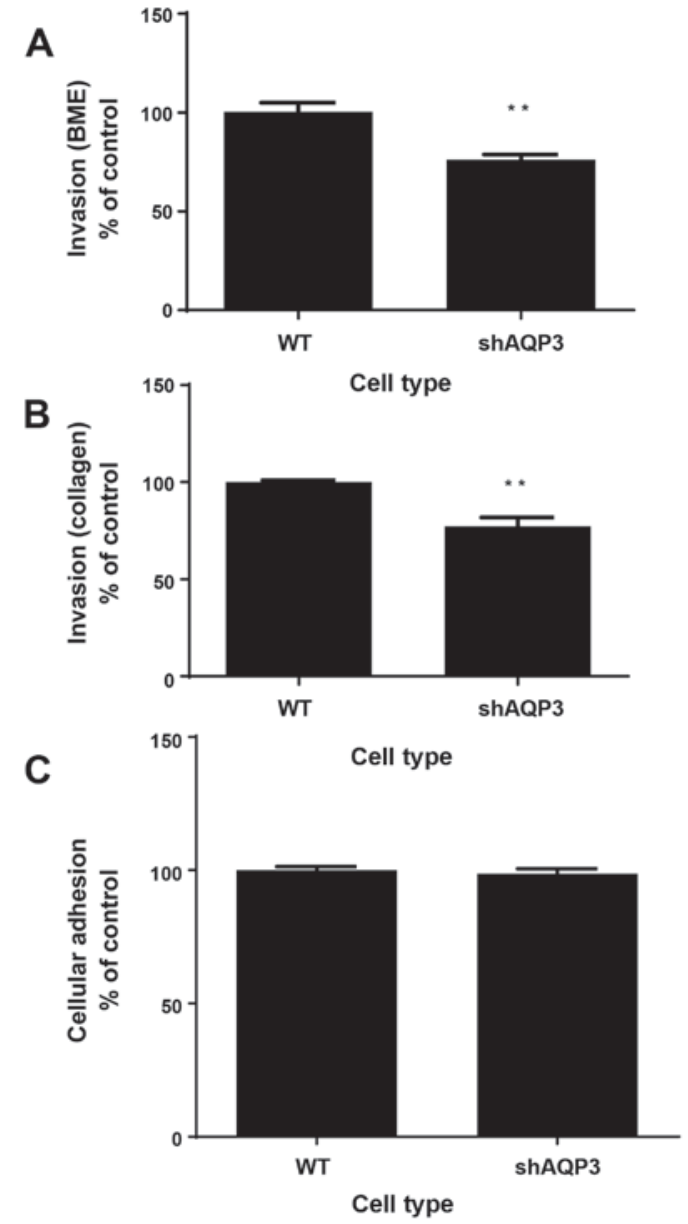

Figure 5. AQP3 mediates cellular invasion but not adhesion. Graphical representation of the relative level of shAQP3 and wild type (WT) invasion through (A) BME substrate and (B) collagen substrate after $24 \mathrm{~h} . \mathrm{n}=8$. ${ }^{* *} \mathrm{P}<0.01$. (C) Cellular adhesion of sh AQP3 and WT cells as measured by calcein AM fluorescence after $4 \mathrm{~h}$ incubation in fibronectin coated plate. $\mathrm{n}=8$. Bars represents mean \pm SEM.

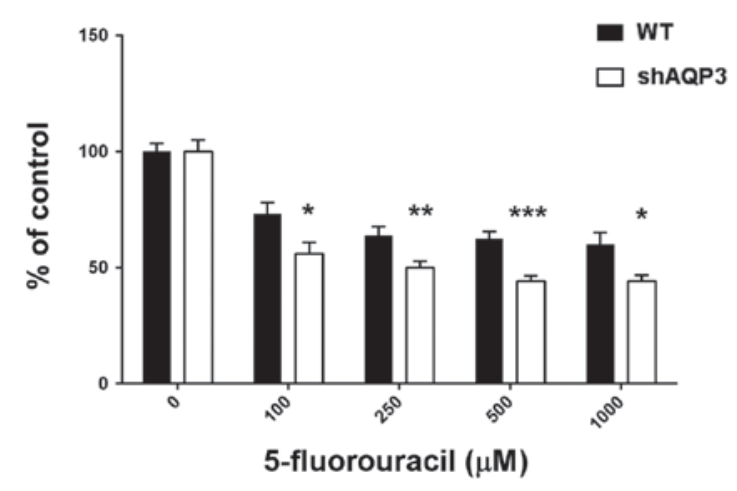

Figure 6. AQP3 gene silencing sensitises MDA-MB-231 cells to 5-fluouracil-induced cell death. Cell viability assay comparing shAQP3 cells and wild type (WT) exposed to 5FU after $48 \mathrm{~h}(\mathrm{n}=6)$. Black bars=WT, open bars $=$ shAQP3. ${ }^{*} \mathrm{P}<0.05,{ }^{* *} \mathrm{P}<0.01,{ }^{* * *} \mathrm{P}<0.001$ vs. WT. Bars represent mean \pm SEM.

to water $(\mathrm{P}=0.016, \mathrm{n}=3)$ compared to control cells (Fig. 7). There was however a more marked decrease in glycerol permeability in shAQP3 cells (Fig. 8), with a 77\% decrease in glycerol permeability being observed $(\mathrm{P}=0.0018, \mathrm{n}=3)$ compared to control cells, suggesting that AQP3 in MDA-MB-231 is preferentially 

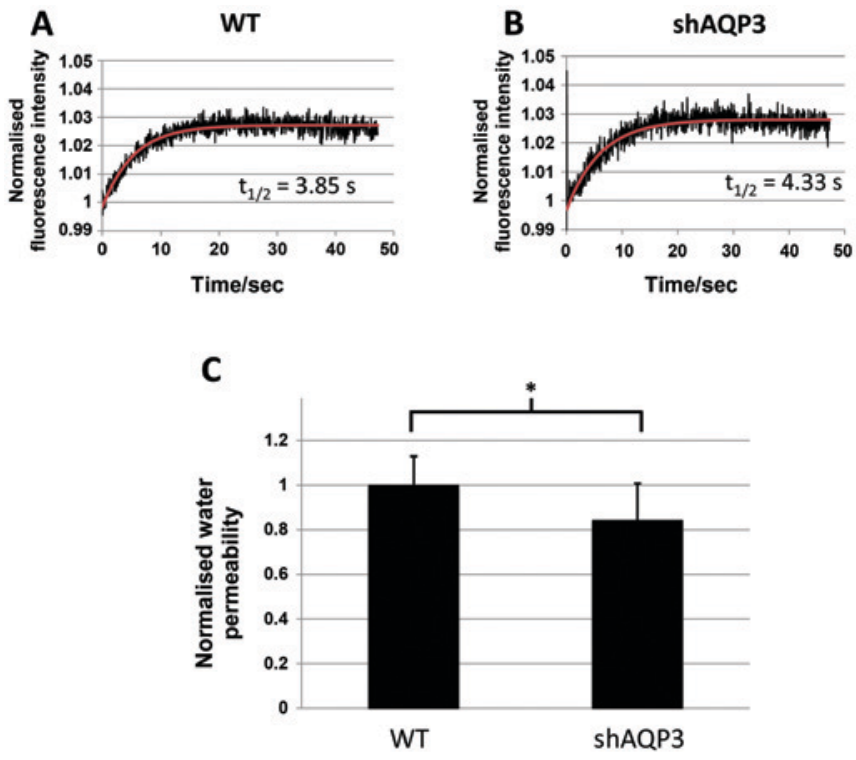

Figure 7. AQP3 gene silencing induces a small decrease in water transport. Representative calcein AM fluorescence intensity time-series of (A) WT and (B) shAQP3 cells subjected to a $85 \mathrm{mOsm}$ inwardly directed osmotic gradient (black), and fitted exponential decay function of the form C-Ae-kt (red). (C) Osmotic water permeability of WT and shAQP3 cells normalised to the average wild type permeability. $n=3$, with each $n$ an average over 3 fluorescence time-series. ${ }^{*} \mathrm{P}<0.05$. Bars represent mean \pm SEM.
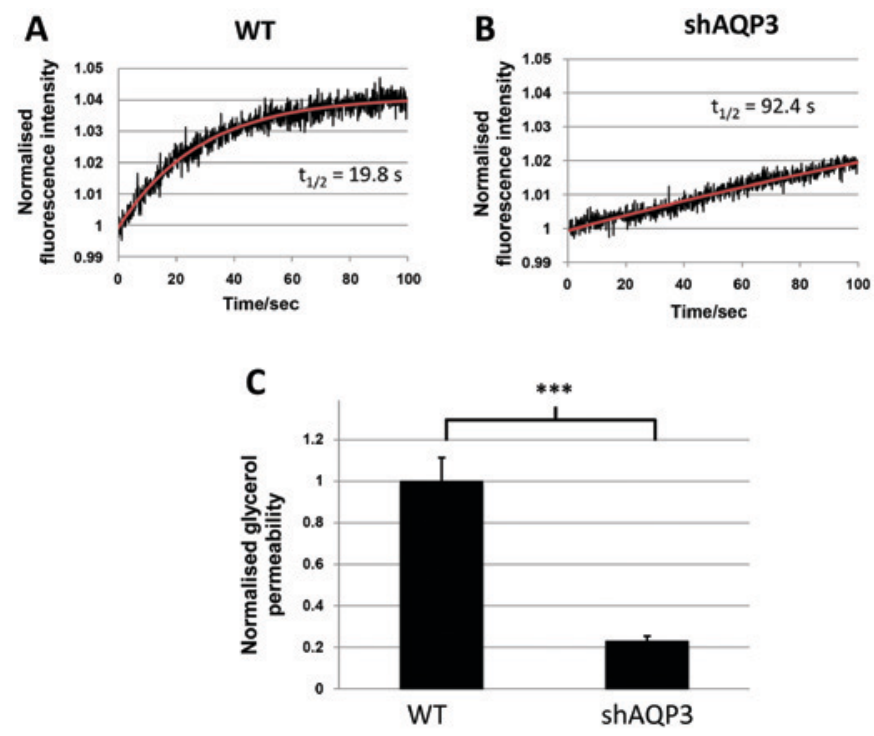

Figure 8. AQP3 gene silencing induces a marked decrease in glycerol transport. Representative calcein fluorescence intensity time-series of (A) WT and (B) shAQP3 cells subjected to a $170 \mathrm{mM}$ inwardly directed glycerol gradient (black), and fitted exponential decay function of the form C-Ae-kt (red). (C) Glycerol permeability of WT and shAQP3 cells normalised to the average wild type permeability. $n=3$, with each $\mathrm{N}$ an average over 3 fluorescence time-series. ${ }^{* * *} \mathrm{P}<0.001$. Bars represent mean \pm SEM.

a glycerol channel and that the effects of AQP3 silencing are likely due to a reduction in glycerol transport.

\section{Discussion}

The rates of breast cancer remain high in most societies, as do the mortality-incidence ratios (38). With this in mind, identification of novel cellular targets for therapeutic interventions is of key importance for developing the repertoire available to clinicians. It is known from previous work that AQP3 is expressed in most epithelia (39) and that expression levels are significantly upregulated in cancerous breast epithelia (40). In addition, previous studies have suggested that AQP3 is involved in oestrogen-induced breast cancer cell migration, invasion and proliferation (23). This study reports for the first time that downregulation of AQP3 expression in breast cancer cells significantly modulates several clinically relevant aspects of breast cancer cell biology.

A key finding presented here is that silencing $\mathrm{AQP} 3$ expression produced a marked reduction in cellular proliferation rate (leading to an increase in the doubling time) in MDA-MB-231 cells. Previous evidence suggests that AQP3 is involved in epithelial cell proliferation (29), although no evidence of this effect in breast epithelial cells has previously been reported. Targeting the proliferation rate of cancerous breast epithelial cells is of great importance as cellular proliferation (measured by Ki67 expression or mitosis counting) has been significantly correlated with disease prognosis in numerous studies $(41,42)$. These data, in combination with the findings presented here, suggest that targeting cellular proliferation by pharmaceutical downregulation or inhibition of AQP3 expression or function is clinically relevant and might be associated with a better prognosis.

We can also report here that knockdown of AQP3 in MDA-MB-231 cells resulted in significant decreases in cellular migration and invasion and that these effects are in addition to the effects on proliferation. Recent data have shown that AQP3 is necessary for fibroblast growth factor-2 induced cell migration in MDA-MB-231 cells (43), suggesting that AQP3 is a key regulator of migration in these cells. These observations are of key importance as they suggest that targeted reduction in AQP3 levels may not only inhibit the ability of tumour cells to proliferate, but also reduce the ability of breast cancer cells to break through a basement membrane and spread to distant sites. Axillary lymph node metastases remains an important prognostic factor for breast cancer, and therefore any intervention that can reduce the capacity of primary breast cancer cells to spread to distant sites is of significant clinical interest.

The mechanism by which AQP3 may influence cellular migration is not known. It has been previously demonstrated that $\mathrm{AQP} 3$ mediated $\mathrm{H}_{2} \mathrm{O}_{2}$ transport, and that this has a potential role in the regulation of breast cancer cell migration (44). Our data show that glycerol permeability is significantly reduced in shAQP3 cells and this reduction is markedly more than that seen for water permeability (Figs. 7 and 8). Whilst this is not mechanistic proof, glycerol transport and possibly its role in cell metabolism may be the mechanism by which reducing AQP3 expression leads to changes in cellular behaviour.

AQP3 represents an exciting target for breast cancer therapy as it fulfils several criteria. First, it is a membrane protein and therefore relatively accessible using traditional pharmaceutical means (45). Secondly, research using AQP3 knockout mice has shown that the only major phenotypic consequences of global AQP3 knockdown are limited to dry skin and reduced wound healing (46-48); although a delay in wound healing is potentially an issue post-operatively, this can hypothetically be overcome by delaying any AQP3-based 
therapy after wound closure is complete. These observations suggest that there may be only limited consequences from using a global approach to reducing either AQP3 expression or function in breast epithelial cells. The lack of potential side effects that might be associated with global AQP3 knockdown is therefore a key strength of using AQP3 as a target for novel therapeutic interventions. This study provides a platform for further work; it would be beneficial to compare the effects of AQP3 in primary breast cancer epithelial cells and a range of other breast cancer cell models (including hormone-sensitive cell lines) as part of a wider programme for the translational impact of this study.

In conclusion, this study reports that AQP3 downregulation reduces breast cancer cell proliferation, migration and invasion in MDA-MB-231 cells whilst increasing sensitivity to the antimetabolite chemotherapy drug, 5-FU. This is the first study to identify AQP3 as a target for breast cancer therapy.

\section{References}

1. Ferlay J, Shin HR, Bray F, Forman D, Mathers C and Parkin DM: Estimates of worldwide burden of cancer in 2008: GLOBOCAN 2008. Int J Cancer 127: 2893-2917, 2010.

2. Justo N, Wilking N, Jönsson B, Luciani S and Cazap E: A review of breast cancer care and outcomes in Latin America. Oncologist 18: 248-256, 2013.

3. Jemal A, Bray F, Center MM, Ferlay J, Ward E and Forman D: Global cancer statistics. CA Cancer J Clin 61: 69-90, 2011.

4. Martino M, Ballestrero A, Zambelli A, Secondino S, Aieta M, Bengala C, Liberati AM,Zamagni C, Musso M, Aglietta M, et al: Long-term survival in patients with metastatic breast cancer receiving intensified chemotherapy and stem cell rescue: Data from the Italian registry. Bone Marrow Transplant 48: 414-418, 2013.

5. Conner AC, Bill RM and Conner MT: An emerging consensus on aquaporin translocation as a regulatory mechanism. Mol Membr Biol 30: 1-12, 2013.

6. Ishibashi K, Kondo S, Hara S and Morishita Y: The evolutionary aspects of aquaporin family. Am J Physiol Regul Integr Comp Physiol 300: R566-R576, 2011.

7. Rojek A, Praetorius J, Frøkiaer J, Nielsen S and Fenton RA: A current view of the mammalian aquaglyceroporins. Annu Rev Physiol 70: 301-327, 2008.

8. Hara-Chikuma M and Verkman AS: Aquaporin-3 facilitates epidermal cell migration and proliferation during wound healing. J Mol Med (Berl) 86: 221-231, 2008.

9. Verkman AS, Hara-Chikuma $M$ and Papadopoulos MC: Aquaporins-new players in cancer biology. J Mol Med (Berl) 86: 523-529, 2008

10. Xie Y, Wen X, Jiang Z, Fu HQ, Han H and Dai L: Aquaporin 1 and aquaporin 4 are involved in invasion of lung cancer cells Clin Lab 58: 75-80, 2012.

11. Zhang Z, Chen Z, Song Y, Zhang P, Hu J and Bai C: Expression of aquaporin 5 increases proliferation and metastasis potential of lung cancer. J Pathol 221: 210-220, 2010.

12. Tie L, Lu N, Pan XY, Pan Y, An Y, Gao JW, Lin YH, Yu HM and Li XJ: Hypoxia-induced up-regulation of aquaporin-1 protein in prostate cancer cells in a p38-dependent manner. Cell Physiol Biochem 29: 269-280, 2012.

13. Otto W, Rubenwolf PC, Burger M, Fritsche HM, Rößler W, May M, Hartmann A, Hofstädter F, Wieland WF and Denzinger S: Loss of aquaporin 3 protein expression constitutes an independent prognostic factor for progression-free survival: An immunohistochemical study on stage pT1 urothelial bladder cancer. BMC Cancer 12: 459, 2012.

14. Li A, Lu D, Zhang Y, Li J, Fang Y, Li F and Sun J: Critical role of aquaporin-3 in epidermal growth factor-induced migration of colorectal carcinoma cells and its clinical significance. Oncol Rep 29: 535-540, 2013.

15. Wang J, Gui Z, Deng L, Sun M, Guo R, Zhang W and Shen L: c-Met upregulates aquaporin 3 expression in human gastric carcinoma cells via the ERK signalling pathway. Cancer Lett 319: $109-117,2012$.
16. Wang G, Gao F, Zhang W, Chen J, Wang T, Zhang G and Shen L: Involvement of Aquaporin 3 in Helicobacter pylori-related gastric diseases. PLoS One 7: e49104, 2012.

17. Li B, Jin L, Zhong K and Du D: Correlation of aquaporin 3 expression with the clinicopathologic characteristics of non-small cell lung cancer. Zhongguo Fei Ai Za Zhi 15: 404-408, 2012 (In Chinese).

18. Liu YL, Matsuzaki T, Nakazawa T, Murata S, Nakamura N, Kondo T, Iwashina M, Mochizuki K, Yamane T, Takata K and Katoh R: Expression of aquaporin 3 (AQP3) in normal and neoplastic lung tissues. Hum Pathol 38: 171-178, 2007.

19. Hara-Chikuma M and Verkman AS: Prevention of skin tumorigenesis and impairment of epidermal cell proliferation by targeted aquaporin-3 gene disruption. Mol Cell Biol 28: 326-332, 2008.

20. Trigueros-Motos L, Pérez-Torras S, Casado FJ, Molina-Arcas M and Pastor-Anglada M: Aquaporin 3 (AQP3) participates in the cytotoxic response to nucleoside-derived drugs. BMC Cancer 12: 434, 2012.

21. Shi Z, Zhang T, Luo L, Zhao H, Cheng J, Xiang J and Zhao C: Aquaporins in human breast cancer: Identification and involvement in carcinogenesis of breast cancer. J Surg Oncol 106: 267-272, 2012.

22. Kang S, Chae YS, Lee SJ, Kang BW, Kim JG, Kim WW, Jung JH, Park HY, Jeong JH, Jeong JY and Park JY: Aquaporin 3 expression predicts survival in patients with HER2-positive early breast cancer. Anticancer Res 35: 2775-2782, 2015.

23. Huang YT, Zhou J, Shi S, Xu HY, Qu F, Zhang D, Chen YD, Yang J, Huang HF and Sheng JZ: Identification of estrogen response element in aquaporin-3 gene that mediates estrogen-induced cell migration and invasion in estrogen receptor-positive breast cancer. Sci Rep 5: 12484, 2015.

24. Vici P, Pizzuti L, Natoli C, Gamucci T, Di Lauro L, Barba M, Sergi D, Botti C, Michelotti A, Moscetti L, et al: Triple positive breast cancer: A distinct subtype? Cancer Treat Rev 41: 69-76, 2015.

25. Lorusso G and Rüegg C: New insights into the mechanisms of organ-specific breast cancer metastasis. Semin Cancer Biol 22: 226-233, 2012.

26. Liang CC, Park AY and Guan JL: In vitro scratch assay: A convenient and inexpensive method for analysis of cell migration in vitro. Nat Protoc 2: 329-333, 2007.

27. Gebäck T, Schulz MM, Koumoutsakos P and Detmar M: TScratch: A novel and simple software tool for automated analysis of monolayer wound healing assays. Biotechniques 46: 265-274, 2009.

28. Ji C, Cao C, Lu S, Kivlin R, Amaral A, Kouttab N, Yang H, Chu W, Bi Z, Di W and Wan Y: Curcumin attenuates EGF-induced AQP3 up-regulation and cell migration in human ovarian cancer cells. Cancer Chemother Pharmacol 62: 857-865, 2008.

29. Levin MH and Verkman AS: Aquaporin-3-dependent cell migration and proliferation during corneal re-epithelialization. Invest Ophthalmol Vis Sci 47: 4365-4372, 2006.

30. Nakahigashi K, Kabashima K, Ikoma A, Verkman AS, Miyachi Y and Hara-Chikuma M: Upregulation of aquaporin-3 is involved in keratinocyte proliferation and epidermal hyperplasia. J Invest Dermatol 131: 865-873, 2011.

31. Du J, Sun C, Hu Z, Yang Y, Zhu Y, Zheng D, Gu L and Lu X: Lysophosphatidic acid induces MDA-MB-231 breast cancer cells migration through activation of PI3K/PAK1/ERK signaling. PLoS One 5: e15940, 2010.

32. Cazet A, Groux-Degroote S, Teylaert B, Kwon KM, Lehoux S, Slomianny C, Kim CH, Le Bourhis X and Delannoy P: GD3 synthase overexpression enhances proliferation and migration of MDA-MB-231 breast cancer cells. Biol Chem 390: 601-609, 2009.

33. Liu L, Duclos G, Sun B, Lee J, Wu A, Kam Y, Sontag ED, Stone HA, Sturm JC, Gatenby RA and Austin RH: Minimization of thermodynamic costs in cancer cell invasion. Proc Natl Acad Sci USA 110: 1686-1691, 2013.

34. Bendas G and Borsig L: Cancer cell adhesion and metastasis: Selectins, integrins, and the inhibitory potential of heparins. Int J Cell Biol 2012: 676731, 2012.

35. Earley S and Plopper GE: Phosphorylation of focal adhesion kinase promotes extravasation of breast cancer cells. Biochem Biophys Res Commun 366: 476-482, 2008.

36. Longley DB, Harkin DP and Johnston PG: 5-fluorouracil: Mechanisms of action and clinical strategies. Nat Rev Cancer 3: 330-338, 2003

37. Fenton RA, Moeller HB, Nielsen S, de Groot BL and Rützler M: A plate reader-based method for cell water permeability measurement. Am J Physiol Renal Physiol 298: F224-F230, 2010. 
38. Forouzanfar MH, Foreman KJ, Delossantos AM, Lozano R Lopez AD, Murray CJ and Naghavi M: Breast and cervical cancer in 187 countries between 1980 and 2010: A systematic analysis. Lancet 378: 1461-1484, 2011.

39. Mobasheri A, Wray S and Marples D: Distribution of AQP2 and AQP3 water channels in human tissue microarrays. J Mol Histol 36: 1-14, 2005.

40. Niu D, Kondo T, Nakazawa T, Yamane T, Mochizuki K, Kawasaki T, Matsuzaki T, Takata K and Katoh R: Expression of aquaporin 3 in human neoplastic tissues. Histopathology 61: 543-551, 2012.

41. Urruticoechea A, Smith IE and Dowsett M: Proliferation marker Ki-67 in early breast cancer. J Clin Oncol 23: 7212-7220, 2005.

42. van Diest PJ, van der Wall E and Baak JP: Prognostic value of proliferation in invasive breast cancer: A review. J Clin Pathol 57 675-681, 2004

43. Cao XC, Zhang WR, Cao WF, Liu BW, Zhang F, Zhao HM, Meng R, Zhang L, Niu RF, Hao XS and Zhang B: Aquaporin3 is required for FGF-2-induced migration of human breast cancers. PLoS One 8: e56735, 2013.
44. Satooka H and Hara-Chikuma M: Aquaporin-3 controls breast cancer cell migration by regulating hydrogen peroxide transport and its downstream cell signaling. Mol Cell Biol 36: 1206-1218, 2016.

45. Rucevic M, Hixson D and Josic D: Mammalian plasma membrane proteins as potential biomarkers and drug targets. Electrophoresis 32: 1549-1564, 2011.

46. Hara-Chikuma M and Verkman AS: Roles of aquaporin-3 in the epidermis. J Invest Dermatol 128: 2145-2151, 2008.

47. Verkman AS: Knock-out models reveal new aquaporin functions. Handb Exp Pharmacol: 359-381, 2009.

48. Hara M, Ma T and Verkman AS: Selectively reduced glycerol in skin of aquaporin-3-deficient mice may account for impaired skin hydration, elasticity, and barrier recovery. J Biol Chem 277: 46616-46621, 2002.

(i) (9) This work is licensed under a Creative Commons Attribution-NonCommercial-NoDerivatives 4.0 International (CC BY-NC-ND 4.0) License. 